\title{
New Species and New Combinations in Sonerila and Phyllagathis (Melastomataceae) from Thailand
}

\author{
Nicoletta Cellinese
}

Botany Department, School of Plant Sciences, University of Reading, Reading RG6 2AS, United Kingdom. Current Address: University of Florida Herbarium (FLAS), 209 Rolfs Hall,

Gainesville, Florida 32611-0530, U.S.A.

\section{Susanne S. Renner}

Department of Biology, University of Missouri-St. Louis, 8001 Natural Bridge Rd., St. Louis, Missouri 63121-4499, U.S.A.

Abstract. While revising the Melastomataceae for the Flora of Thailand, we discovered two new species of Sonerila, as well as the need for transferring two species of Tylanthera endemic to Thailand into Phyllagathis. Sonerila urceolata and $S$. loeiensis are endemic to the southeast and the northeast of Thailand, respectively. The first is allied to the widespread $S$. erecta Jack, from which it differs mainly in the strongly urceolate capsule and the sessile fruit placenta; the second is distinguished from other acaulescent species of Sonerila by its extremely long-petiolate large leaves and long-pedunculate inflorescence. The new combinations, Phyllagathis tuberosa (Hansen) Cellinese \& Renner and $P$. siamensis Cellinese \& Renner nom. nov., are made because both taxa lie inside the morphologic and phylogenetic bounds of Phyllagathis.

During work on the Melastomataceae for the Flora of Thailand (Renner et al., in press), we came across Tylanthera Hansen, a genus based on two collections from Thailand of plants similar in habit, but representing two species (Hansen, 1990). Both species have a tuber or rhizome with a stunted growth and one or a few growing points, producing one to few long-petiolate membranaceous leaves and a single inflorescence (Figs. 1, 2). Both also have four stamens and no staminodes. According to Hansen the 4-merous haplostemonous flowers of the two species precluded their placement in Phyllagathis, a closely related genus that normally has 4-merous but diplostemonous flowers. Both species resemble Phyllagathis spp. in capsule morphology (the capsules have relatively thin tops), inflorescence structure (scorpioid cymes or umbels), and stamen morphology (the connectives are dorsally thickened). As pointed out by Hansen, an androe- cium of only four stamens is uncommon in the Sonerileae but occurs in a few species of Phyllagathis sensu lato (including Aschistanthera Hansen, Brittenia Cogniaux ex Boerlage, Cyanandrium Stapf, Cyphotheca Diels, Enaulophyton Steenis, Kerriothyrsus Hansen, Scorpiothyrsus Li, and Tigridiopalma Chen), such as $P$. tetrandra Diels from southern China. In general, there is a pronounced tendency in the Sonerileae, a large pantropical tribe, to reductions in the androecium, with the inner set of stamens becoming staminodial (Renner, 1993). Also, in a monophyletic Phyllagathis (Cellinese et al., monograph in prep.) it is clear that haplostemony has arisen several times. Another feature shared by species of Phyllagathis and the two species of Tylanthera is the dorsally thickened connective (Figs. 1, 2). A dorsally and/or ventrally thickened or appendaged connective also occurs in some species of Phyllagathis, such as the Bornean $P$. pachystachya Hansen.

A third character adduced by Hansen to justify placing at least one of the two species in a separate genus was the ellipsoid seed shape of $T$. $t u b$ erosa (see Hansen (1990) for SEM photographs of the seeds of T. tuberosa and T. cordata). He suggested that such seeds were unknown in Phyllagathis. However, a comparison of the seeds of $T$. cordata and T. tuberosa (Hansen, 1990: fig. 3) shows that they are very similar in testa surface and shape, except for the somewhat less well developed beak in T. tuberosa. Note that most Sonerileae investigated have beaked seeds and that seed shape is therefore of little help in the generic placement of species in this tribe. (Seed SEMs resulting from Hansen's work have been incorporated into the Copenhagen herbarium and are sent on loan together with the respective material.) Because Tylanthera as circumscribed by Hansen

Novon 7: 106-112. 1997. 

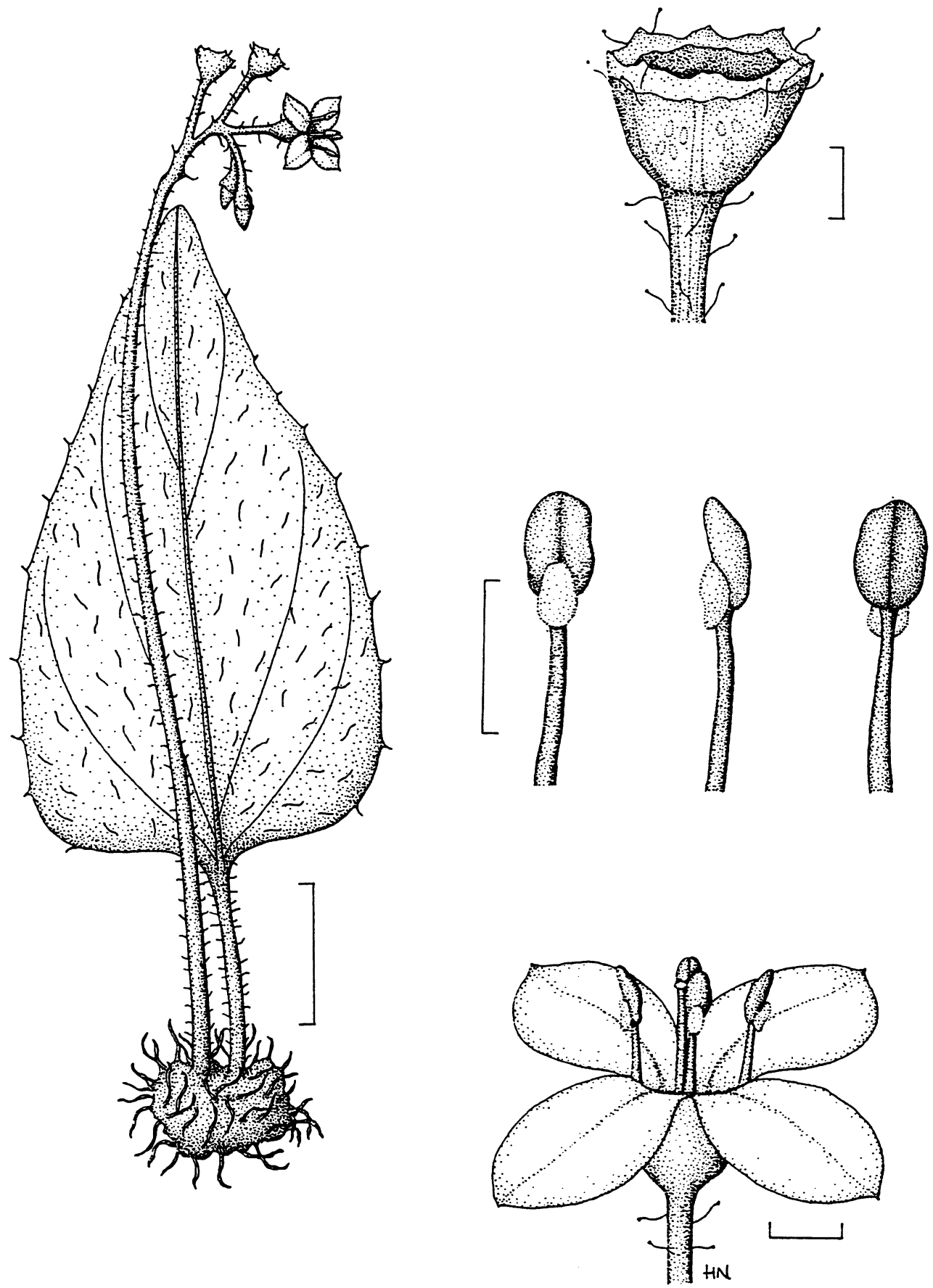

Figure 1. Phyllagathis tuberosa (Hansen) Cellinese \& S. S. Renner. Habit; scale bar $=1 \mathrm{~cm}$. Flower; scale bar $=1$ $\mathrm{mm}$. Dorsal, lateral, and ventral views of stamen; scale bar $=2 \mathrm{~mm}$. Capsule; scale bar $=1 \mathrm{~mm}$.

thus lacks diagnostic features as well as synapomorphies that could be construed as supporting its monophyly, we see no reason to continue excluding these two species from Phyllagathis, with which they share so many traits.
The two species are clearly distinct. Tylanthera tuberosa (Fig. 1) has a scorpioid cyme, the connective is dorsobasally enlarged into a peltate appendage, and the ovary lacks apical scales; the inflorescence of $T$. cordata (= Phyllagathis sia- 


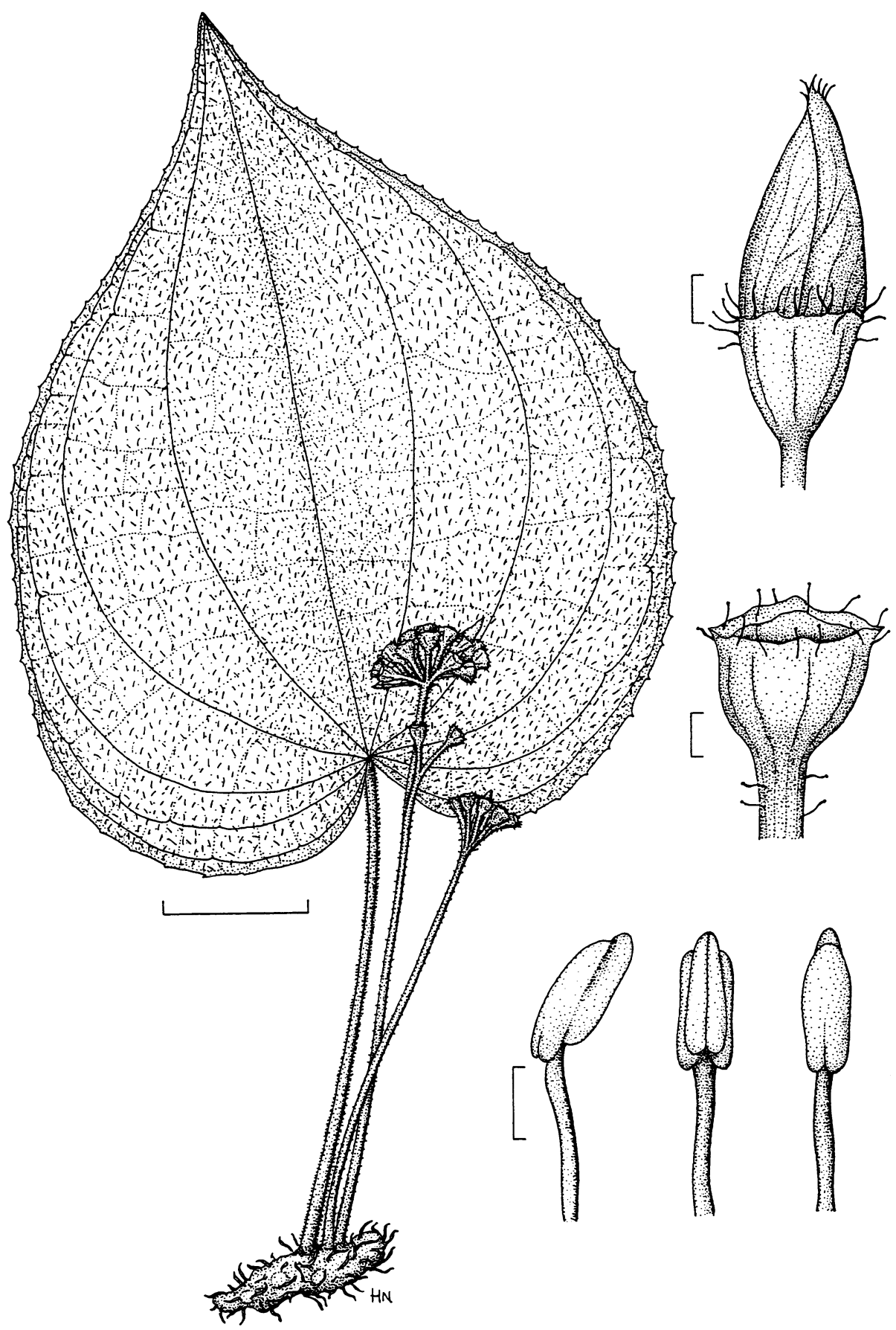

Figure 2. Phyllagathis siamensis Cellinese \& S. S. Renner. Habit; scale bar $=1 \mathrm{~cm}$. Lateral, ventral, and dorsal views of stamen, capsule, and flower bud; scale bars $=1 \mathrm{~mm}$. 


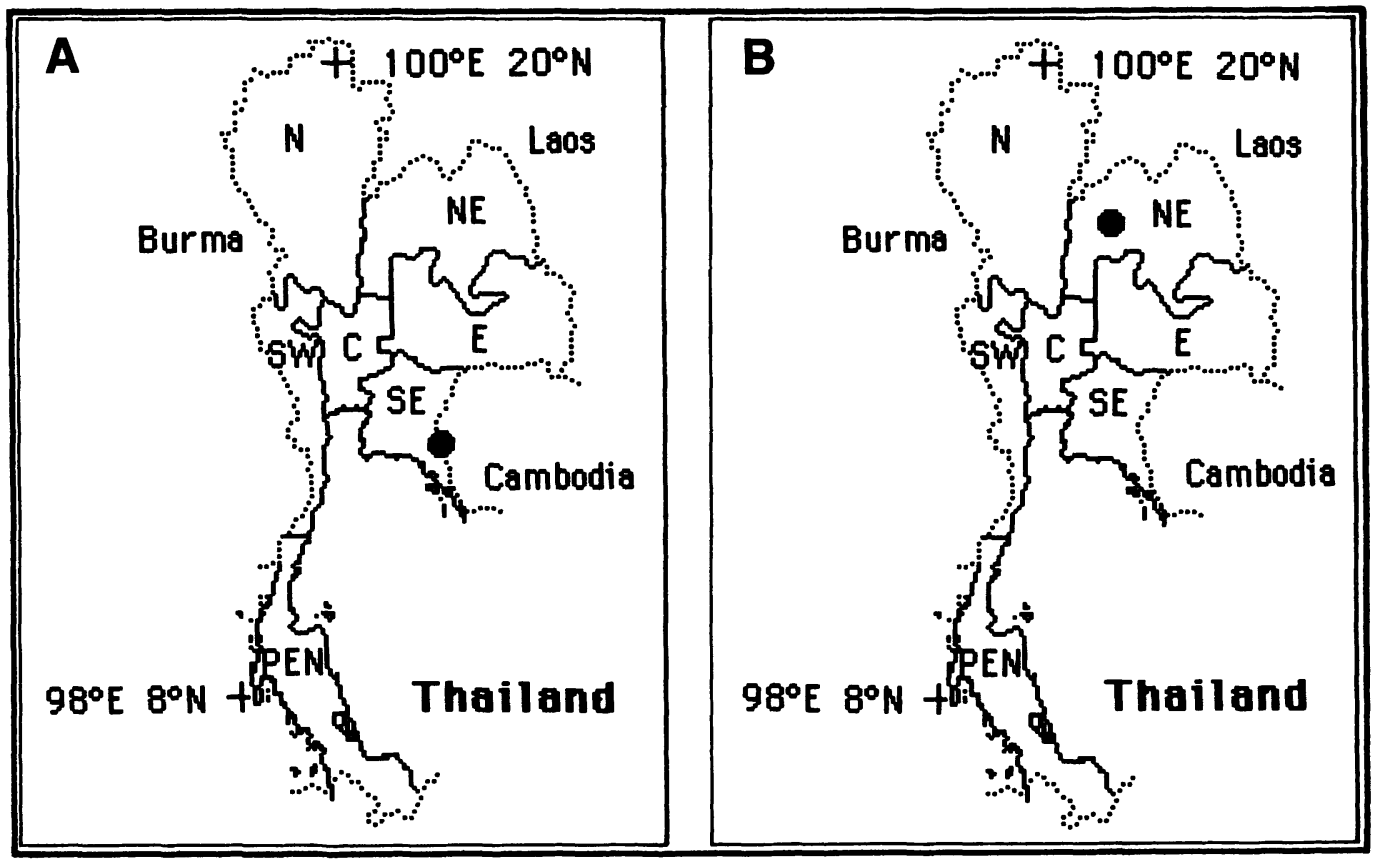

Figure 3. - A. Distribution of Sonerila urceolata. - B. Distribution of Sonerila loeiensis.

mensis, Fig. 2) by contrast is an umbel, the connective is enlarged into a flat ridge along the length of the thecae, and the ovary has four large apical lobes.

Phyllagathis tuberosa (Hansen) Cellinese \& S. S. Renner, comb. nov. Basionym: Tylanthera tuberosa Hansen, Nordic J. Bot. 9: 632. 1990. TYPE: Thailand. Northern: Phitsanulok: Phu Mieng mountain, $700 \mathrm{~m}$ alt., July-Aug. 1966, Larsen et al. 1105 (holotype, AAU; isotypes, $\mathrm{BKF}, \mathrm{C})$. Figure 1.

Phyllagathis siamensis Cellinese \& S. S. Renner, nom. nov. Basionym: Tylanthera cordata Hansen, Nordic J. Bot. 9: 634. 1990. TYPE: Thailand. Central: Sarika Falls at Nakhon Nayok, $300 \mathrm{~m}$ alt., 1968, Larsen et al. 3402 (holotype, AAU; isotypes, BKF, C). The new name is necessary because the epithet is occupied by Phyllagathis cordata Ridley. Figure 2.

Sonerila, with between 100 and 175 species (Lundin, 1983, and pers. estimate), is the largest genus in the Sonerileae. It is the only consistently trimerous genus in the family and as such easily diagnosed. Thirteen species occur in Thailand, most of them herbaceous except for S. helferi C. B. Clarke and $S$. spectabilis Nayar, which are somewhat woody. Sonerila urceolata occurs in southeast
Thailand (Fig. 3A) and resembles $S$. erecta in general habit but is unusual in Sonerila in having urceolate capsules. The second species described here, $S$. loeiensis, is endemic to northeast Thailand (Fig. 3B) and differs from other acaulescent Thai species in having very long-petiolate membranaceous leaves, similar to those of $S$. wallichii Bennett from Mysore and S. plagiocardia Diels from Yunnan, species from which it differs in the much shorter inflorescence stalk.

Sonerila urceolata Cellinese \& S. S. Renner, sp. nov. TYPE: Thailand. Southeast: Chantaburi, Khao Soi Dao North, Wildlife Sanctuary, Pong Namron District, 300-800 m alt., 26 Nov. 1979, Shimizu et al. 23595 (holotype, BKF; isotypes, AAU, L). Figure 4.

A Sonerila erecta Jack capsula longa $(8-9 \mathrm{~mm})$ glabra, urceolata, basis applanatis, parte superiore fusca, persistentibus calycibus coronata differt.

Erect branched herb, to $50 \mathrm{~cm}$ tall and sometimes basally woody, the stem subterete, glandularpilose mainly along two opposite longitudinal lines. Leaves of a pair subequal and slightly asymmetric, lanceolate, $1.2-4.3 \times 0.6-1.5 \mathrm{~cm}$, the base acute or attenuate, the apex acute to acuminate, the margin serrulate and ciliate, the lamina 3-nerved, sparsely covered by minute glands, the petiole $0.2-$ $0.9 \mathrm{~cm}$ long, covered with sparse glandular hairs. 


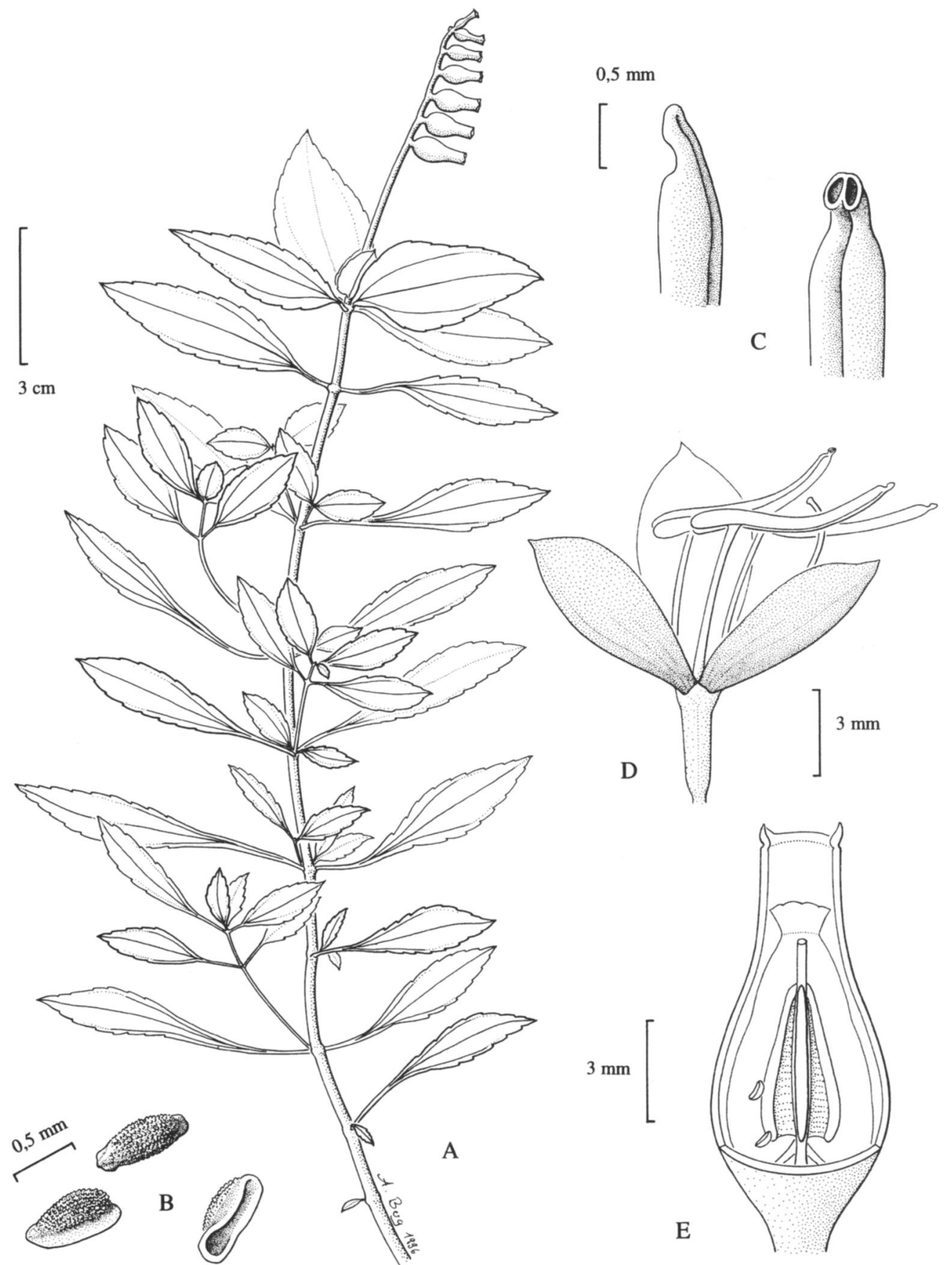

Figure 4. Sonerila urceolata Cellinese \& S. S. Renner. -A. Habit. -B. Seeds. -C. Apical part of stamen. -D. Flower. -E. Longitudinal section of a capsule.

Inflorescence a terminal 2-7-flowered scorpioid cyme, to $3 \mathrm{~cm}$ long, the peduncle $2.5-5.3 \mathrm{~cm}$ long, subtended by two asymmetrical bracteoles. Flowers 3-merous, the pedicels $1-3 \mathrm{~mm}$ long. Hypanthium cylindrical, about $6.5 \times 3 \mathrm{~mm}$, the calyx lobes tri- angular, ca. $1 \mathrm{~mm}$ long, acuminate. Petals about 1.3 $\times 0.6 \mathrm{~cm}$, ovate with an acuminate tip, purple. Stamens 3 , the filament $7-8 \mathrm{~mm}$ long, the anthers about $13 \mathrm{~mm}$ long, opening by two pores, yellow, the pollen sacs prolonged and free at the base, with 
a distinct apical constriction. Ovary about $4 \mathrm{~mm}$ long, adnate to the hypanthium by 3 septs, crowned by 3 conspicuous scales, the style ca. $1.4 \mathrm{~cm}$ long, the stigma peltate. Capsule urceolate, 8-9 $\times 3-5$ $\mathrm{mm}$, crowned by the persistent calyx lobes, glabrous, the placentae subsessile, elongated, attached to the column by several filiform stalks (in old fruits). Seeds obovate with a lateral beak, $1 \mathrm{~mm}$ long, tuberculate.

Flowering and fruiting: November.

Endemic to southeast Thailand where it grows in dry evergreen forest along ravines. The epithet refers to the characteristic urceolate capsules that make the species easily recognizable at least in fruit. Sonerila urceolata resembles the widespread $S$. erecta Jack in habit, indumentum, inflorescence type, and in having two-porate anthers. Sonerila erecta occurs in southeast Thailand where the new species was discovered, but has a much smaller subcylindrical capsule. Also, the old fruit placenta in $S$. erecta is distinctly stalked.

Sonerila loeiensis Cellinese \& S. S. Renner, sp. nov. TYPE: Thailand. Northeast: Loei, Phu Rua National Park, summit road, vicinity of Turtle Rock, 30 Sep. 1990, Chantaranothai et al. 482 (holotype, TCD). Figure 5.

Sonerilae wallichii Bennett affinis sed pedunculo minori differt.

Acaulescent herb, ca. $22 \mathrm{~cm}$ tall, the vegetative parts glabrous, rhizome short and thick. Leaves few, ovate, $2.8-8.3 \times 1.6-4.5 \mathrm{~cm}$, the base obliquely truncate to subcordate, the apex acute, the margin denticulate, the lamina 7-plinerved, membranaceous, the nerves reddish, the upper surface dark green, the lower surface pale green, the petiole subquadrangular, to $12.3 \mathrm{~cm}$ long. Inflorescence an umbel, 3-5-flowered, the peduncle $5-5.5 \mathrm{~cm}$ long. Flowers 3 -merous, the pedicel ca. $3 \mathrm{~mm}$ long, with a few stiff bristly hairs. Hypanthium cylindric, ca. $5 \times 2 \mathrm{~mm}$, the calyx lobes triangular, less than $1 \mathrm{~mm}$ long, acute. Petals about $1.2 \times 0.5 \mathrm{~cm}$, elliptic with an acuminate tip, pink. Stamens 3 , the filament $5-6 \mathrm{~mm}$ long, the anthers about $9 \mathrm{~mm}$ long, opening by a single pore, pale yellow, slender and attenuate, pollen sacs prolonged and free at the base. Ovary about $4 \mathrm{~mm}$ long, adnate to the hypanthium by 3 septs for about $2 / 3$ along its length, crowned by 3 scales, the anther pockets rather deep, the style ca. $1.1 \mathrm{~cm}$ long, the stigma peltate. Capsule unknown.

\section{Flowering: September.}

Endemic to northeast Thailand, where it was found growing on rocks. The holotype has a tera-

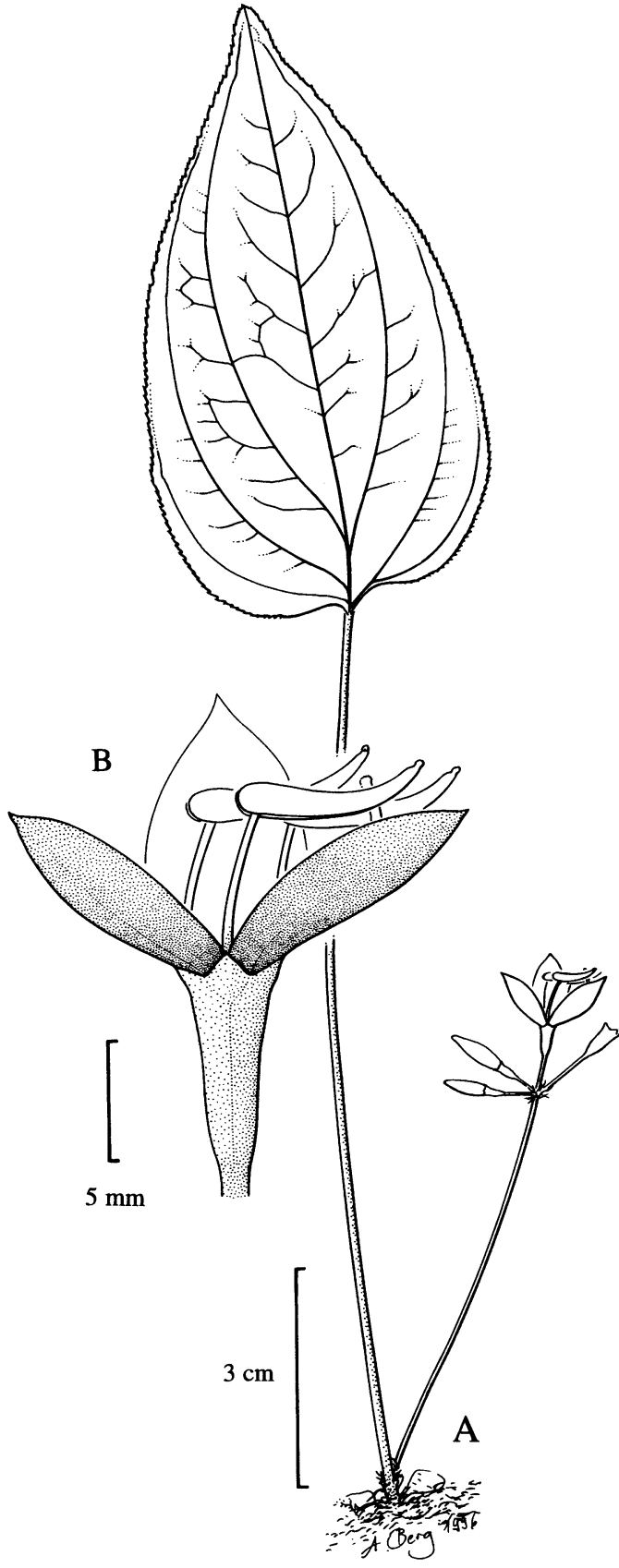

Figure 5. Sonerila loeiensis Cellinese \& S. S. Renner. -A. Habit. - B. Flower.

tological flower in which floral mery has doubled: it has six petals, two whorls of three equal stamens, and a six-celled ovary with two styles. As discussed above, occasional switching from one to two whorls and vice versa sometimes occurs in the Sonerileae, but we know of no published description of this particular mutation. 
Acknowledgments. This research was supported by a grant from the EU Human Capital and Mobility Programme "Biodiversity in the Indo-Pacific Region" and was completed in the Department of Systematic Botany of the University of Mainz, Germany. We thank Anke Berg, Mainz, for Figures 4 and 5, Holly Nixon, Dublin, for Figures 1 and 2, and the curators of AAU, BKF, C, L, and TCD for loans of material under their care.

\section{Literature Cited}

Hansen, C. 1990. Tylanthera (Melastomataceae), a new genus of two species endemic to Thailand. Nordic J. Bot. 9: 631-635.

Lundin, R. 1983. Taxonomy of Sonerila (Melastomataceae) in Ceylon. Nordic J. Bot. 3: 633-656.

Renner, S. S. 1993. Phylogeny and classification of the Melastomataceae and Memecylaceae. Nordic J. Bot. 13: 519-540.

G. Clausing, N. Cellinese \& K. Meyer. In press. Melastomataceae. In K. Larsen \& I. Nielsen (editors), Flora of Thailand. The Forest Herbarium, Royal Forest Department, Bangkok, Thailand. 